Hispania Sacra, LIX

120, julio-diciembre 2007, 707-740, ISSN: 0018-215-X

\title{
PEDRO POVEDA EN CLAVE HISTORIOGRÁFICA: UN DEBATE CULTURAL Y PEDAGÓGICO DEL SIGLO XX
}

\author{
POR \\ Armando Pego Puigbó \\ Universitat Ramon Llull
}

\section{RESUMEN}

En este artículo se procura ofrecer una panorámica de la recepción historiográfica de la vida y la obra del sacerdote y pedagogo Pedro Poveda (1874-1936). Se presentan así los rasgos de una singular propuesta pedagógica católica en una época secularizada. Poveda quiso hacer presente el mensaje cristiano en las estructuras educativas estatales animando el diálogo entre fe y ciencia. Este programa de modernización comprende también las claves hermenéuticas de una época marcada por las actividades de la ILE.

PAlABRAS ClAVE: Pedro Poveda, Siglo XX; Historia religiosa, Historia de la educación, Política educativa, Institución Libre de Enseñanza.

\section{ABSTRACT}

In this paper a view on the historiographic reception of the life and works of the priest and pedagogue Pedro Poveda (1874-1936) is tried to offer. The characteristic features of his catholic pedagogical proposal are showed in the context of a secularized age. Poveda looked forward to making the Christian message present into the educational structures of the State through a dialogue between faith and science. This program for modernization implies the hermeneutic tools of a period marked by the activities of the ILE.

KEY WORDS: Pedro Poveda, XXth Century; Religious History, History of Education, Educational Policy, Institucion Libre de Enseñanza.

Recibido/Received 29-03-2007

Aceptado/Accepted 03-05-2007 
La figura de Pedro Poveda (Linares, 1876-Madrid, 1936), sacerdote y pedagogo español del primer tercio del siglo XX, fundador de la Institución Teresiana, habría de cobrar un renovado protagonismo en las circunstancias sociales y políticas de la España e incluso de la Europa de comienzos del siglo XXI. Tal protagonismo ha estado oscurecido por un conjunto de factores históricos, pedagógicos y religiosos que conviene analizar y repensar en un momento en que se están discutiendo los límites de la laicidad en las sociedades democráticas occidentales.

En las siguientes páginas centraré mi exposición, por un lado, en las razones historiográficas que parecen haber preterido la originalidad de la obra povedana y, por otro, en los nuevos caminos que se están abriendo en el estudio de uno de los personajes clave de la educación española -no sólo católica- desde la etapa final de la Restauración hasta la II República. Se quiere contribuir así a la recepción y al análisis de una de las propuestas más singulares del catolicismo español del siglo XX desde una comprensión cultural.

Por ello, primero me detendré a analizar la acogida bibliográfica del protagonista y su obra tanto desde el campo propiamente civil como confesional. A continuación, plantearé algunas de las paradojas que se han producido a la hora de estudiar su aportación pedagógica (biografías, análisis histórico-social del contexto, historia de la Institución Teresiana, etc.). Concluiré con un balance de las perspectivas de futuro que ofrecen las investigaciones actuales sobre nuestro autor y las huellas que pueden dejar en el modo de enfocar el estudio de la historia religiosa contemporánea.

\section{Pedro Poveda, ¿Una cita a Pie de página?}

Setenta años después de su muerte, al observar en perspectiva la imagen de Pedro Poveda proyectada por la bibliografía eclesiástica o/y pedagógica, se tiene la sensación de no haber podido reivindicar del todo a otro de los grandes olvidados de la cultura española contemporánea. Hay varias razones. Unas, políticas. Entre ellas, su trágica muerte el 28 de julio de 1936, en los primeros días de la Guerra Civil española. Otras son religiosas, como su empeño por inculturar la fe cristiana mediante el ejercicio profesional de mujeres laicas, principalmente en la enseñanza pública. A eso se añade, como explicación cultural, el desconocimiento de sus escritos.

$\mathrm{Ni}$ su reconocimiento como «humanista y pedagogo» por la UNESCO en 1974, en el centenario de su nacimiento, ni su beatificación en 1993 ni su canonización en 2003 han supuesto una difusión mayor de su vida y de su obra, escasamente difundida entre el gran público, malinterpretada o reducida en su originalidad a unos esquemas que no dan cuenta de su complejidad ni de sus matices.

Hispania Sacra, LIX

120, julio-diciembre 2007, 707-740, ISSN: 0018-215-X 
Poveda no fundó, en modo alguno, una nueva Congregación Religiosa dedicada a la enseñanza, sino que, por primera vez, aun apoyándose en experiencias similares en el terreno de la enseñanza privada -como las Asociaciones de maestros promovidas por el jesuita P. Tarín ${ }^{1}$, diseñó un programa que quería ofrecer a los maestros y las maestras cristianas la posibilidad de organizarse y de participar en el proceso de construcción de una escuela nacional de carácter estatal desde los presupuestos de su fe. Inspirado por el modelo teológico y espiritual de «los primeros cristianos», ciudadanos iguales en derechos y deberes a los demás en una sociedad inmersa en un periodo de secularización, escribió en 1911 el Ensayo de un proyecto pedagógico ${ }^{2}$. A raíz de esta publicación, fundó la que más tarde se conocería como Institución Teresiana. En tanto que asociación de mujeres laicas dedicadas a la enseñanza, primordialmente la pública, su ideal comenzó a cristalizar en torno a las Academias como centros de formación que, en estrecha colaboración con las Escuelas Normales oficiales, deseaban contribuir a lograr el objetivo último de hacer presente el mensaje cristiano, mediante una adecuada preparación de las profesionales del magisterio, en las estructuras educativas estatales.

Tanto la importancia concedida al carácter asociativo, en sintonía con las preocupaciones profesionales y pedagógicas de la época, como el impulso dado al papel protagonista que la mujer podía llegar a adquirir en el ámbito académico, comenzando por la primera enseñanza, convierten a Poveda en un pensador y organizador que no puede quedar circunscrito sin más al ámbito de la «inteligencia» católica. Debería ser estudiado en el contexto histórico de una de las etapas más fecundas de la cultura española, por la que se dejó influir y en la que quiso incidir. Téngase en cuenta además su constante preocupación social, desde sus años de joven sacerdote en Guadix, donde en 1902 fundó unas escuelas para los niños y las niñas de las cuevas, hasta el final de su vida, tras haber sido miembro tanto de la Junta Central contra el Analfabetismo como de la Hermandad del Refugio. Como ha dicho Dolores Gómez Molleda,

\footnotetext{
1 «La creación de asociaciones de maestros católicos no ha sido estudiada todavía documentalmente, pero los archivos de la madrileña, zaragozana, catalana o de Sevilla, están esperando los trabajos interesantes que puedan demostrarnos el éxito del Congreso Católico de Sevilla (1892) en este campo» (Bernabé Bartolomé Martínez, «Los Congresos Católicos (1889-1902) y los problemas de la educación. Las confederaciones y su contribución a la enseñanza en la escuela católica», en Bernabé BARTOLOMÉ (dir.), Historia de la acción educadora de la Iglesia en España. II. Edad Contemporánea, Madrid, BAC, 1996, p. 184).

${ }^{2}$ Hubo en 1912 una segunda edición ampliada, con el título de Ensayo de proyectos pedagógicos. Le siguieron dos escritos de carácter educativo, Simulacro pedagógico (1912) y Diario de una fundación (1912). Maria Grazia MARA, «Una espiritualidad de encarnación: como los primeros cristianos», en Evangelizar hoy: Una Nueva Cultura, una Historia distinta, Madrid, Narcea, 1993.
} 
«su preocupación por la educación de las clases populares, por la asociación profesional de los maestros y su promoción social, por la actualización pedagógica del profesorado y la renovación de los métodos de enseñanza, y sus realizaciones en el campo social-educativo, lo sitúan en un puesto relevante dentro del movimiento educativo moderno y reformista» ${ }^{3}$.

En su madurez, su innovadora visión del apostolado laical, a través de la presencia cristiana en las estructuras estatales, refleja precisamente la profunda huella del proceso de modernización que experimentó la sociedad española entre la Revolución del 68 y la II República y que tuvo en el regeneracionismo finisecular un punto de especial relevancia. Tratando de superar una postura confesional marcada por el celo catequístico, Poveda procuró sintonizar el testimonio ejemplar de vida cristiano con una formación científica acorde con las exigencias del momento, más allá de las polémicas sobre la enseñanza del catecismo, manteniéndose al mismo tiempo fiel al magisterio papal. Para él, fe y ciencia no se contraponían, en un momento en que determinados sectores lo sostenían con convicción. Lo que cabía hacer, en su opinión, era, por el contrario, articular este diálogo, teniendo en cuenta las complejas relaciones de poder de una sociedad que demandaba la autonomía de la vida pública: «Pensar en la modificación de la legislación vigente, cuando cada nueva ley es un paso más hacia el laicismo, sería pensar en un remedio irrealizable $\gg^{4}$. Frente a esta actitud y mediante la fundación de la que llamaba la Institución Católica de Enseñanza, que no logró materializar, proponía en Ensayo de proyectos pedagógicos:

«formar, según el espíritu cristiano y ajustándose a los mejores métodos pedagógicos, un cuerpo de profesores de primera enseñanza, a quienes presentará anualmente a oposiciones a fin de obtener el mayor número de plazas en las oposiciones a escuelas públicas; y segundo, mantener por todos los medios posibles, y a costa de los mayores esfuerzos, el espíritu cristiano y la unión profesional en todos los profesores que pertenezcan a la Institución» ${ }^{5}$.

Asumiendo la novedad de tal planteamiento, así como el difícil equilibrio que provocó esta apuesta al situarse en las fronteras de la praxis católica habitual aquellos años, las siguientes páginas procurarán dar cuenta tanto de la re-

${ }^{3} \mathrm{M}^{\mathrm{a}}$ Dolores Gómez Molleda, La escuela, problema social (En el Centenario de Poveda), Madrid, Narcea, 1974, p. 27.

${ }^{4}$ Pedro Poveda, Cuadernos Varios, apógrafos, citado por Ma ${ }^{a}$ Dolores Gómez Molleda, «Estudio introductorio», en Pedro PovedA, Obras I. Creí, por esto hablé, edición crítica, Madrid, Narcea, 2005, p. L.

${ }^{5}$ Pedro Poveda, Itinerario pedagógico, estudio preliminar, edición y notas de Ángeles Galino, Madrid, CSIC, $1965^{2}$, p. 111. Hay edición facsímile de los tres principales folletos pedagógicos (Pedro Poveda, Folletos, Madrid, Publicaciones de la Institución Teresiana, 1989) (para nuestra cita, vid. p. 67).

Hispania Sacra, LIX

120, julio-diciembre 2007, 707-740, ISSN: 0018-215-X 
cepción historiográfica de esta propuesta como de indicar las posibles líneas de fuerza en que se inscribe, haciéndolas y haciéndose así históricamente inteligibles. De otro modo, habría que reconocer, con Cioran, que, en el caso concreto de Poveda, tiene una irónica validez afirmar que «el hombre hace la historia; a su vez, la historia lo deshace a él. Él es su autor y su objeto, su agente y su víctima» 6 .

Creo conveniente, por tanto, confrontar la actitud ante la figura de Pedro Poveda de quienes lo observan desde la distancia de una cultura laica en sentido estricto y de quienes, en cambio, ven en él un maestro para vivir cristianamente la vocación educativa y científica en esa misma realidad laica. Podrá percibirse que las opiniones entre ambos grupos no son sin más contrarias sino que, en ocasiones, pueden ser complementarias y que, dentro de un mismo grupo y no sólo en el interior de cada uno, pueden existir también discrepancias. En todo caso, de todas ellas se verán emerger lugares decisivos de interpretación que suscita el fundador de la Institución Teresiana y que pueden ayudar también a explicar el por qué de su eclipse historiográfico.

\section{Andrés MANJón y PedRo Poveda, SOBRE El FONDO DEL CATOLICISMO SOCIAL}

El problema principal en la recepción historiográfica de Poveda ha procedido de establecer una comparación entre su reflexión pedagógica y la de Andrés Manjón. Las consecuencias que se derivan afectan tanto al nivel biográfico como histórico, social y pedagógico. Es indudable que las Escuelas del Sagrado Corazón de Jesús que organiza en Guadix en 1902 y que se verá obligado a abandonar en 1905, por graves problemas en la diócesis y con el obispo Maximiano Fernández del Rincón, nacen influidas por la potente obra de las Escuelas Ave-Marianas del canónigo del Sacro Monte. Hasta tal punto esta conexión ha calado tan hondo que se ha considerado toda su obra posterior una continuación de esta labor de regeneración social en nuevas circunstancias y ante nuevos retos.

Así, en su monumental obra dedicada a la Institución Libre de Enseñanza, Antonio Jiménez Landi destaca que, entre las fundaciones católicas, sólo hay dos excepciones capaces de asimilar los avances de la moderna pedagogía: «las escuelas creadas por el padre Manjón en Granada y la fundación de los centros por el también sacerdote Pedro Poveda». Y añade: «en ambos casos se acusa un curioso influjo de la ILE, no como inspiradora de la ideología a la que respondían las fundaciones de Manjón y Poveda, sino como un ejemplo de la necesi-

${ }^{6}$ Emmanuel M. Cioran, Desgarradura, Barcelona, Tusquets, 2004, p. 44. 
dad de reformar la enseñanza y como un hecho con el que había que contar» ${ }^{7}$. Tenemos así el armazón que marca y, a menudo, confunde la evolución intelectual de Poveda: por un lado, la influencia de Manjón; por otro, la (difícil) relación con la ILE.

Veamos con un poco más de detenimiento esta línea de interpretación. Para Manuel de Puelles, muy beligerante, la diferencia fundamental entre Manjón y Poveda procede de que mientras aquél «inicia su experiencia en solitario y lejos de la lucha del siglo, el padre Poveda participa de la lucha de la Iglesia contra la secularización de la enseñanza». Según Puelles, «obsesionado» por la ILE, idea un antídoto con la Institución Católica de Enseñanza que pretende formar profesores católicos destinados a la enseñanza oficial. Concluye que, fracasado este intento, «en su lugar surgieron las academias que, ciertamente, significaban un nuevo estilo en la docencia confesional, especialmente volcado hacia la formación de una minoría selecta» ${ }^{8}$. Se ha producido, pues, un cambio en la valoración de la obra povedana. Mientras para Jiménez Landi las Academias equivalían a las escuelas manjonianas, para Puelles representan un esfuerzo por oponerse directamente a la labor de la ILE. Con una valoración más positiva, Rosa Capel, situando la Institución Teresiana en el ámbito del catolicismo social, señala que fue «la obra más completa y arraigada de cuantas iniciativas renovadoras adoptaron los sectores católicos en el campo educativo». Salvando las distancias, «podíamos decir que trataba de ser el «alter ego» en femenino y católico de la ILE»9.

En efecto, Manjón no entra de lleno en el conflicto ideológico entre Iglesia y Estado a propósito de la educación hasta 1902, cuando sus escuelas estaban ya asentadas y comenzaban a extenderse por la Península ${ }^{10}$. Habían merecido grandes elogios de amplios los sectores de la vida española desde 1898. Sus métodos fueron innovadores, a la altura de los que los institucionistas estaban simultáneamente desarrollando: desde la enseñanza continua, basada en juegos y otras actividades al aire libre, hasta la importancia concedida al ejercicio físico y a las colonias de verano. En todos ellos fue un precursor junto con Francisco Giner de los Ríos. José Castillejo, Secretario de la Junta para la Ampliación de Estudios desde su creación en 1907, reconocería durante los primeros años de la Guerra Civil en su exilio londinense:

7 Antonio Jiménez Landi, La Institución Libre de Enseñanza. III. Periodo escolar. 1881-1907, Madrid, Ministerio de Educación y Cultura, 1996, p. 321.

8 Manuel de Puelles BeNítez, Educación e ideología en la España contemporánea, Madrid, Tecnos, $1999^{4}$, p. 252.

${ }^{9}$ Rosa M ${ }^{\mathrm{a}}$ CAPEl MARTínez, El trabajo y la educación de la mujer en España (1900-1930), Madrid, Ministerio de Educación-Instituto de la Mujer, 1986², pp. 353-354.

${ }^{10}$ Yvonne Turin, La educación y la escuela en España de 1874 a 1902, Madrid, Aguilar, 1967, p. 273

Hispania Sacra, LIX

120, julio-diciembre 2007, 707-740, ISSN: 0018-215-X 
«Prácticamente, sin ninguna otra preparación filosófica, psicológica o educativa que el Evangelio y Santo Tomás, y confiando en su sentido común, se dedicó con generosidad y perseverancia al desarrollo de su escuela, a la invención de métodos y a la instrucción de maestros [...] Y Manjón, como Giner, tenía dedicación y creía más en la moral y la conducta que en la erudición» ${ }^{11}$.

Puede decirse que las escuelas ave-marianas, fundadas en 1889, constituyen, por tanto, una respuesta católica a las necesidades de regeneración social que se siente en España desde la última década del siglo XIX y que eclosionan con motivo de la fecha paradigmática de 1898. Respuesta que, por otra parte, concuerda con los criterios del catolicismo social promovido por la encíclica Rerum Novarum de León XIII y que arraigan en España también en esta década final ${ }^{12}$.

Ahora bien, como hemos señalado, cuando se habla de la aportación de Poveda no se remite a las escuelas de la Ermita Nueva de Guadix sino al programa que diseña durante su estancia en Covadonga como canónigo (1906-1913), cuya aplicación dará lugar a la creación de las Academias. Primero fundó en julio de 1911 la de Gijón, dirigida a maestros, que no llegó a ponerse en marcha, y en noviembre, la de Oviedo y después, en 1912, la de Jaén, ambas dirigidas a y por mujeres. En cuanto centros de enseñanza, implícitamente ha quedado justificada para una gran parte de la bibliografía más afín a las coordenadas povedanas la continuidad entre unas y otras fundaciones y, en suma, la vinculación de ambas con la labor de Manjón y, en consecuencia, con la «regeneración» social a través de la educación y la cultura ${ }^{13}$.

Bajo esta perspectiva Poveda formaría parte, desde el ámbito eclesiástico, de ese grupo de hombres que lucharon por sentar las bases de una transformación social desde una aguda conciencia patriótica y religiosa. Ésta es la posición inicial, luego matizada, que sostiene Angeles Galino. Allí señala que, en Covadonga, «su actitud íntima es la de sus años juveniles: dolorida vivencia de la situación social y cultivo esperanzado del principal instrumento de regeneración: la formación cristiana del pueblo» ${ }^{14}$. Es cierto que para Galino el año 1909 es cla-

\footnotetext{
11 José Castillejo, Guerra de ideas en España, Madrid, Revista de Occidente, 1976, p. 92.

12 Feliciano Montero García, El primer catolicismo social y la «Rerum Novarum» en España (1889-1902), Madrid, CSIC, 1983.

${ }^{13}$ En un artículo recién publicado sobre la labor de la Junta para la Ampliación de Estudios en Asturias durante los primeros años de su funcionamiento, no se cita en absoluto la Academia de Oviedo, pese a estar dirigida por profesoras de la Escuela Normal. Se menciona sólo a Luis Huerta, uno de los dos primeros colaboradores de Poveda, en relación con sus estudios sobre higienismo como pensionado de la JAE (Aida TERRÓN BAÑUELO, « ¿Recoger y sembrar? La complejidad de la innovación educativa analizada en un contexto regional. El caso de Asturias», Revista de Educación, número extraordinario 2007, pp. 117-142).

14 Ángeles Galino, «Estudio Preliminar», en P. PovedA, op. cit., p. 23.
} 
ve en el descubrimiento de la misión de alcance nacional de Poveda ${ }^{15}$. En todo caso, ese año supuso la ampliación, la profundización y el desarrollo de las inquietudes iniciales que desembocaron en la creación de las escuelas guadijeñas.

Llevado al extremo, la Institución Teresiana, en cuanto que surge del programa povedano puesto en marcha por medio de las Academias, es presentada así en el contexto del debate sobre el titular del derecho a educar: o la familia y, por extensión, la Iglesia, o el Estado. En suma, «la labor regeneradora de la educación es, según él [Poveda], el factor imprescindible de elevación del nivel cultural, profesional y convivencial entre los españoles» ${ }^{16}$.

Resumiendo. Las Escuelas del Sagrado Corazón de Jesús, fundadas en la Ermita Nueva de Guadix en 1902, se encuentran, según esta perspectiva, en la estela del regeneracionismo católico. Su fundación se produce, asimismo, en un contexto general de renovación pedagógica que alienta toda una serie de iniciativas tanto en el campo privado como en el oficial ${ }^{17}$. Las similitudes con las escuelas manjonianas se muestran evidentes desde un primer momento. El 14 de febrero de 1903 Manjón anota en su Diario: «El Sr. Obispo de Guadix me dice que en la capital de su diócesis ha fundado un familiar suyo un remedo del AveMaría con grande éxito» ${ }^{18}$. Un año después, en abril de 1904, Poveda edita un folleto para recaudar fondos para sus escuelas que se ponen bajo la autoridad moral de Andrés Manjón:

«La obra es un pobre remedo de las Escuelas del insigne P. Manjón. Los métodos y procedimientos que usamos son los mismos que allí tienen, copiados y aprendidos allí. Nos honramos en imitar un modelo tan excelente» ${ }^{19}$.

Pero, de hecho, esta nueva fundación no había surgido tal cual como la del Ave-María. A Manjón le impactó el estado de abandono de los niños y las niñas del Sacro Monte y se dispuso a atenderlos mediante la enseñanza. Poveda se acerca a las cuevas con la finalidad de una catequesis que enseguida da lugar a unas misiones (diciembre 1901-mayo 1902). Entre el conjunto de iniciativas

\footnotetext{
15 Ibíd., p. 26.

16 Ángela DEL VALLE LÓPEZ, «Órdenes, Congregaciones e Institutos Eclesiásticos femeninos dedicados a la educación y enseñanza», en B. BARTOLOMÉ (dir.), op. cit., p. 645.

${ }^{17} \mathrm{M}^{\mathrm{a}}$ Dolores Peralta Ortiz, «Las Escuelas del Sagrado Corazón de la Ermita Nueva en el contexto educativo y social de comienzos del siglo XX», Boletín del Instituto de Estudios Pedro Suárez 15 (2002): 146-181.

${ }^{18}$ Andrés Manjón, Diario. 1895-1923, introducción y texto crítico de José Manuel Prellezo García, Madrid, BAC, 2003 (2 edición revisada y ampliada), p. 293.

19 Pedro Poveda, Escuelas del Sagrado Corazón de Jesús establecidas en las Cuevas de la Ermita Nueva de Guadix, Guadix, Imprenta de Flores, 1904, p. 4 (facsímile en Madrid, Publicaciones del Archivo de la Institución Teresiana, 2004).
}

Hispania Sacra, LIX

120, julio-diciembre 2007, 707-740, ISSN: 0018-215-X 
que surgen para aplicar la doctrina social pontificia, el movimiento misional y catequético ocupa un lugar muy destacado. Este modelo misional, fuertemente marcado por la personalidad del ya mencionado P. Tarín, influye decisivamente en el espíritu de Poveda durante los años de Guadix, como lo prueba el hecho de que decidiese recorrer la comarca en busca de fondos para sus escuelas en julio de 1904, una vez abortado el festival, que había de cumplir estas expectativas, en homenaje a Gonzalo de Figueroa, Conde de Mejorada, protector de las escuelas. Circunstancias todas ellas que acabarán volviéndose contra Poveda y obligándole a abandonar la diócesis.

De todos estos datos podemos sacar algunas conclusiones que ponen en cuestión la relación unívoca Manjón-Poveda-ILE. Las escuelas avemarianas son originales en su concepción, independientemente de las aportaciones pedagógicas de Giner de los Ríos y sus discípulos. Manjón entrará en polémica con el modelo educativo de la ILE con posterioridad a la fundación de sus escuelas y al desarrollo de sus métodos pedagógicos más conocidos. En cambio, Poveda inicia la actividad de sus Academias bajo el foco del conflicto secularizador entre Iglesia y Estado, en un momento en que comienzan a desarrollarse una serie de medidas que permiten a la ILE dirigir la política educativa del país: en 1907, se funda la Junta para la Ampliación de Estudios; en 1909, se abre la Escuela Superior de Magisterio; en 1911, Rafael Altamira es nombrado Director General de Primera Enseñanza. Todas estas fechas coinciden con su estancia en la basílica de Covadonga, desde donde entra en contacto con la Universidad de Oviedo, un centro de fuerte influjo institucionista por la presencia de profesores como Adolfo Posada, Aniceto Sela, Adolfo Buylla o el propio Altamira ${ }^{20}$. Si los proyectos de Poveda estuvieran marcados por estos acontecimientos, incluso si se les considerase dentro de un clima de reacción católica, como apunta Eugenio Otero Urtaza aludiendo a la Academia Católica impulsada desde 1908 por el que llegaría a ser cardenal Enrique Reig, eso los situaría en un marco diferente, si bien no excluyente, del regeneracionismo social en sentido estricto ${ }^{21}$.

Como conclusión provisional podría decirse que Poveda, discípulo de Manjón al fundar las escuelas guadijeñas, no lo es en su actitud ante la ILE. Manjón no se «opone» a la ILE con la creación del Ave-María, que tiene una dimensión regeneradora mirando a unas circunstancias locales concretas. Cuando se opone a la ILE, lo hace para denunciar el intento de secularización que convierte al Estado en el director y organizador de la vida escolar. Manjón arremete contra el Estado que quiere imponer la educación obligatoria, en la medida que se

\footnotetext{
${ }^{20}$ Flavia Paz Velázquez, Meditación de Covadonga (Cuadernos Biográficos no 3 Pedro Poveda), Madrid, Narcea, 1987, pp. 70-91.

${ }^{21}$ Eugenio M. Otero Urtaza, Manuel Bartolomé Cossío. Trayectoria vital de un educador, Madrid, CSIC-Residencia de Estudiantes, 1994, p. 256.
} 
arroga el deber de enseñar que, para la Iglesia, pertenece a los padres y, siendo católicos los padres en una España católica, ha de revertir en la Iglesia. Poveda, por el contrario, sostendrá, a partir de Covadonga y en su Ensayo de proyectos pedagógicos, que a los cristianos les cabe formarse y organizarse para ocupar plazas en la enseñanza oficial que el Estado quiere hacer extensiva al conjunto de la sociedad.

En este sentido, resulta lícita considerar la Institución Católica de Enseñanza ideada por el canónigo de Covadonga como una réplica a la ILE. De ahí que la Institución Teresiana, como realización concreta de tal proyecto, haya podido ser juzgada como su equivalente católico en cuanto a la búsqueda de una reforma pedagógica que logre la transformación social: no la búsqueda de la transformación social en sí misma sin más, sino el análisis de las condiciones y la puesta en práctica de los métodos que la hagan posible, siendo el Estado, en este sentido, el instrumento decisivo para la consecución de tal objetivo. Como ha dicho Fernando Millán, «la Institución Teresiana y la Institución Libre de Enseñanza, desde planteamientos ideológicos opuestos, coinciden necesariamente, en cuanto creen en la educación como método de transformación del individuo, en la necesidad de la reforma pedagógica de la escuela española» 22 .

LA APORTACIÓN PEDAGÓGICA DE POVEDA EN PERSPECTIVA BIOGRÁFICA: ENTRE REGENERACIONISMO Y MODERNIDAD

La huella que el programa pedagógico de la Institución Libre de Enseñanza haya podido imprimir en el pensamiento de Pedro Poveda constituye un asunto de importancia decisiva para calibrar no sólo la capacidad de diálogo del sacerdote linarense con el mundo laico sino en especial el alcance propiamente moderno de su propuesta. Y, junto con la repercusión educativa, queda también pendiente de analizar en profundidad el aprendizaje por parte de Poveda de las estrategias de penetración de la ILE en la política educativa del momento. En juego se encontraba la posibilidad de llevar a la práctica un modelo de sociedad que respondiese a las necesidades del nuevo modelo de Estado nación, tan sobresalientemente representado por la Francia de la III República. La escuela era el campo decisivo donde se libraría esta batalla, por usar una terminología bélica tan querida a los sectores católicos de comienzos del siglo XX.

Por desgracia, la turbulenta historia española a lo largo del último siglo ha hecho prácticamente imposible poner en relación historiográfica a ambos gru-

\footnotetext{
${ }_{22}^{2}$ Fernando Millán, La revolución laica, de la Institución Libre de Enseñanza a la Escuela de la República, Valencia, Fernando Torres Editor, 1983, p. 192.

Hispania Sacra, LIX

120, julio-diciembre 2007, 707-740, ISSN: 0018-215-X
} 
pos, exasperando la polarización que la política educativa de la II República española había generado. Identificada por los católicos de entonces con los objetivos de la ILE, parecían las propuestas y tácticas de ésta incompatibles de raíz con el espíritu cristiano. Con todo, no se ha podido negar sino que se ha afirmado la concomitancia de intereses y hasta el efecto provocado en sectores católicos por la metodología institucionista ${ }^{23}$.

Es evidente que el rechazo de la enseñanza confesional por parte de Giner y de sus seguidores representa una alternativa radical pedagógica y hasta antropológica, al catolicismo. No menos obvio, sin embargo, resulta que unos y otros han de coincidir, al menos, en el hecho de que participan en el debate sobre el modelo de escuela, un tema decisivo, con consecuencias determinantes en la construcción de una sociedad. Así, Prellezo llega a afirmar sobre Manjón que «se halla en plena sintonía con el ambiente cultural contemporáneo». Eso justifica que «en cierto modo, se podría considerar la escuela manjoniana como una réplica católica a la escuela gineriana» 24 . En el caso de Poveda, en otro sentido, se ha podido decir que era un «reformador contemporáneo», en la medida que procuró superar la esterilidad de un debate reducido a la repetición sistemática de los propios argumentos -y la descalificación de los de los adversarios-presentando «un programa afirmativo, de realizaciones concretas y tangibles, de formación humana, de colaboración positiva. Un estilo frustrado hasta entonces» ${ }^{25}$.

Con todo, la explicación de esta «colaboración positiva», que tocaba de lleno y muy principalmente el terreno de la escuela pública, nunca ha llegado a explicitar cómo se configuró en el diálogo con la ILE, el núcleo intelectual que generó la mayor parte de la reforma educativa del primer tercio del siglo XX. En otro lugar, he procurado plantear las bases de la importancia de esta relación, tan tensa y difícil como fructuosa, para la elaboración de los proyectos po-

${ }^{23}$ Aparte de la bibliografía citada, resultan singularmente valiosas las páginas que dedica José Manuel Prellezo a las lecturas pedagógicas de A. Manjón, incluso entre autores no católicos (Alcántara, Benot...) (J. M. Prellezo, Educación y Familia en Andrés Manjón. Estudio histórico-crítico, Zurich, Pas-Verlag, 1969, pp. 279-319) Se ha llegado a establecer un paralelismo entre Giner de los Ríos y Manjón y sus sendos pensamientos pedagógicos. Pero se trata de un paralelismo «enfrentado» como ejemplificación de dos modelos que, siendo ambos renovadores, son, en último término, antagónicos (Alfonso CAPITÁn DíAz, Los humanismos pedagógicos de Francisco Giner de los Ríos y Andrés Manjón, Granada, Universidad, 1980). Para observar las diferencias de un modo comparado y no paralelo, sobre un tema clave, sigue siendo de enorme utilidad el artículo de J. M. PRELLEZo, «Notas sobre coeducación. Pensamiento de F. Giner y A. Manjón», Orientamenti pedagogici 17 (1979): 776-795. En el caso de Poveda, faltan todavía estudios, pero se hallan en curso de realización, sobre su biblioteca y lecturas.

24 José Manuel Prellezo, Educación y Familia... pp. 292 y 297.

25 Dolores Gómez MolledA, Los reformadores de la España contemporánea, Madrid, CSIC, 1981, p. 482. 
vedanos ${ }^{26}$. Ahora me interesa resaltar las causas y las consecuencias para la imagen de Poveda que se desprenden del estudio de su actitud ante las propuestas y los métodos de los institucionistas.

En su rico y documentado «Estudio introductorio» al primer volumen de las Obras de Poveda, Gómez Molleda sitúa el programa de éste bajo la metáfora de «Atenas y Jerusalén, una propuesta de encuentro recíproco». Leyendo esas páginas, lo observamos comprometido con su tiempo, abierto al diálogo, tratando de superar el prejuicio de unos y otros sobre la incompatibilidad de la fe y la ciencia. Pero, ¿con quién se nos dice que dialoga? Con el foco intelectual de Lovaina y con las figuras del neotomismo, al tiempo que mantiene relación con los sectores más inquietos del catolicismo español, como la Asociación Católica Nacional de Propagandistas ${ }^{27}$. De Giner se cita nada más su crítica a la religiosidad superficial de los españoles. A Altamira o Castillejo, ni se les menciona. La labor de la ILE a favor del primer feminismo está completamente difuminada. Quizás haya que buscar en un párrafo significativo el por qué esta preterición:

\begin{abstract}
«El contacto de Poveda con uno de los grupos más relevantes de intelectuales españoles -la Institución Libre de Enseñanza- influyó, sin duda, en sus reflexiones sobre el mundo cultural hispano. Pero a ello debemos añadir otro factor no menos importante; el movimiento de renovación de la cultura cristiana, que irradió a todo el mundo desde el foco de Lovaina potenciado por el impulso de León XIII»28.
\end{abstract}

Como comentaré más adelante, situar a Poveda en un contexto amplio, intelectual, político, social y religioso, resulta de capital importancia para percibir mejor no sólo su originalidad sino también la importancia de su contribución a la España del momento. Ahora bien, nos queda la duda de cómo este discurso católico, de filiación europea, completamente ortodoxo y al mismo tiempo de frontera, es introducido por su protagonista en el interior del debate ideológico español en torno a la escuela, cuyo interlocutor principal era la ILE, importadora a su vez de ideas de Europa. Como vengo diciendo, se nos sustrae la explicación de la acogida por parte del autor del Ensayo de proyectos pedagógicos (1911) de un hecho decisivo, aunque no se omiten alusiones a las reformas emprendidas por la élite liberal ${ }^{29}$.

${ }^{26}$ Armando Pego Puigbó, Modernidad y pedagogía en Pedro Poveda (La experiencia de Covadonga), Salamanca, Universidad Pontificia, 2006, pp. 224-264.

${ }^{27}$ Dolores GómEZ MolLEDA, «Estudio introductorio», op. cit., pp. LXX-LXXI. Para la labor en la Acción Católica de la Asociación Católica Nacional de Propagandistas, véase José Manuel Ordovas, Historia de la A. C. N. de P. De la Dictadura a la Segunda República (1923-1936), Pamplona, Eunsa, 1993, pp. 83-111.

${ }^{28}$ Dolores Gómez MolledA, «Estudio introductorio», en P. PovedA, Obras I. Creí, por esto hablé, Madrid, Narcea, 2005, p. LXXVI.

${ }^{29}$ Ibíd., p. CXLIV.

Hispania Sacra, LIX

120, julio-diciembre 2007, 707-740, ISSN: 0018-215-X 
Sorprende tanto más esta ausencia cuanto suele presentársele como un adelantado del Concilio Vaticano II en sintonía con la Gaudium et spes ${ }^{30}$. Además de en el diálogo del pensamiento cristiano con las nueva ideología tecno-científica, esta constitución dogmática ha contribuido a profundizar en la comprensión del fenómeno de la «inculturación». Si para Poveda la ILE representaba sólo un referente cultural sobre el que se proyectaban los tópicos acusadores como los que Ramón Ruiz Amado sintetizaba en algunos de sus libros ${ }^{31}$, no puede decirse con rigor ni que el fundador de la Institución Teresiana estuviera realmente inculturado ni que ofreciese un modelo nuevo de colaboración (¿¡ja quién!?). A lo sumo, cabría reconocerle haber pergeñado una estrategia católica de contención, por más audaz que fuera situarla en el centro de la escuela pública, ante el avance de la secularización. Por todo ello, resultarán de especial relevancia los estudios encaminados a dilucidar esta relación, la cual ha sido ya convenientemente aludida en las investigaciones povedanas de Gómez Molleda ${ }^{32}$.

¿Por qué, pues, esta ausencia en la bibliografía povedana, que, por otra parte, no niega, porque es imposible, el marco institucionista en que se desenvuelve la reflexión de este sacerdote? Quizás por una combinación de razones pedagógicas, históricas y biográficas. Siendo fundamentales las primeras, es necesario resaltar la importancia de las dos últimas en la configuración de una imagen de Poveda que se ha asentado como canónica, fuertemente vinculada a una concreta interpretación de la Obra por él fundada.

No cabe duda que quien fue sacerdote en las cuevas de Guadix y canónigo en la basílica de Covadonga poseía una idea de educación y un modelo de educador singulares y propios, con rasgos originales, manifiestos en el tipo de educación que se impartía en sus Academias, y que han sido rastreados y puestos de relieve por sus estudiosas ${ }^{33}$. La voz personal se habría despertado en las cue-

30 Ibid, p. LXXXVII.

31 «Desde que vivo en Madrid, me he dado cuenta de que aquí hay tres cosas subterráneas: el Metro, el alcantarillado... y la Institución Libre de Enseñanza. Ésta defiende sólo y a ultranza la libertad de la cátedra, esto es: la libertad del error». R. RUIZ AMADO, Los peligros de la Educación Nacional. Planes y progresos de la Institución Libre de Enseñanza, Barcelona, Librería Religión, 1923, pp. 41-42.

32 Confiemos que en el segundo volumen de las Obras, en preparación, dedicado a los Ensayos y proyectos pedagógicos, este vacío hermenéutico sea llenado, teniendo en cuenta además el amplio y profundo conocimiento que su responsable tiene del mundo institucionista. De todos modos, sorprende que, en la página de créditos del primer volumen, se indica que se trata de una «edición restringida»; noticia tanto más extraña cuanto que un ejemplar de él puede consultarse en la Biblioteca Nacional de Madrid. Este tipo de decisiones editoriales desorientan a la hora de una recepción desapasionada de una figura tan compleja y, a la vez, tan desconocida de la Iglesia Católica española.

33 Cabe destacar de Margarita BARTOlomé PINA, «El educador en la propuesta educativa de Pedro Poveda», en Atreverse a educar. Congreso de Pedagogía: Pedro Poveda Educador, vol. II., Madrid, Narcea, 1998, pp. 79-107; o la conferencia «Las claves pedagógicas de Pedro Poveda» (2-12-2006), http://www.institucionteresiana.org/asp/documentos/2006/120506/ClavesPP-Bartolome.pdf 
vas de Guadix (1902), para acabar de madurar en Covadonga. Entre una y otra fase podría establecerse, pues, una línea recta, in crescendo, que desembocaría en el Ensayo de proyectos pedagógicos (1911), el Simulacro pedagógico (1912), el Diario de una fundación (1912) y la recopilación de artículos Alrededor de un proyecto (1913), y que continuaría su curso sin solución de continuidad hasta su muerte. Se producirían, sí, ajustes de objetivos, los cuales, en todo caso, responderían las circunstancias concretas sin alterar jamás la evolución «coherente» del catolicismo social comprometido con la acción evangelizadora, en que se puede inscribir a Poveda:

«Entre la sensibilidad social de Poveda, manifestada en Guadix y sus actividades posteriores hasta 1936 no existe ruptura alguna. Cambia el sujeto sobre el que su actividad se concentra, el educando, y adquiere centralidad en sus proyectos el educador, como agente privilegiado para la transformación de la sociedad. Pero la finalidad sigue siendo la misma, una acción evangelizadora capaz de renovar la vida humana en todos los órdenes» ${ }^{34}$.

Este cambio se produce en función de «la articulación que Poveda establece entre educación, promoción humana y social», cuyo análisis será realizado en el segundo volumen de las Obras, actualmente en preparación ${ }^{35}$. Esta interpretación, avalada por la preocupación social que animó siempre a las Academias teresianas (escuelas nocturnas para obreras, escuelas dominicales, etc), parece ser confirmada plenamente por unas líneas de la correspondencia de Poveda en 1934 citadas repetidamente:

«Confieso ingenuamente que al subir yo a las cuevas de Guadix con un grupo de mis seminaristas, no pensé en otra cosa sino en una catequesis; que de nuestras visitas a la ermita de la Virgen de la Gracia, titular de aquel sagrado recinto, medio cueva, medio capilla, surgió el plan de las escuelas y que la vocación a este género de apostolado tuvo su origen allí y las cambiantes posteriores, hasta llegar a la realización de su última etapa, la Institución Teresiana, ante otra imagen de nuestra Señora en la Santa Cueva de Covadonga... La primera vocación en cuanto al tiempo, no en cuanto al mérito ni al valer, fue la mía y ésta es de la Virgen de la Gracia. Esto es pensar alto, si bien compendiando la historia de muchos años» ${ }^{36}$.

Expresiones como «las cambiantes posteriores», «última etapa»y «la primera vocación» plantean, a mi modo de ver, dudas interpretativas que no auto-

\footnotetext{
${ }^{34}$ Dolores GómEZ MoLLEDA, «Estudio introductorio», p. CXLV.

35 Ibid..

${ }^{36}$ Pedro Poveda, correspondencia, 3 de septiembre de 1934, Archivo Histórico de la Institución Teresiana (AHIT), citado por Carmen AZAUSTRE, «Mirada inquieta sobre la tierra de Guadix», en Giovanna Bombardieri y Cira Morano (eds.), Pedro Poveda: Nuevos caminos en la Iglesia, Salamanca, Universidad Pontificia, 2004, p. 40.
}

Hispania Sacra, LIX

120, julio-diciembre 2007, 707-740, ISSN: 0018-215-X 
rizan a concluir que su autor tuviera autoconciencia de la linealidad de su trayectoria intelectual. Sostengo, en consecuencia, que entre Guadix y Covadonga no puede afirmarse sin más la continuidad, sin que por ello sea posible ni lógico negar la influencia de las escuelas guadijeñas en la evolución de Poveda. Digámoslo claramente: sin la experiencia de Guadix, los proyectos pedagógicos de Covadonga no habrían sido posibles; con sólo Guadix -y ello implica el universo cultural del catolicismo social-, la reflexión en Covadonga no habría llegado adonde llegó. En lugar de ruptura, cabría hablar de «reinvención» existencial, con el bagaje, sin duda, de la formación y la memoria personal.

Como esta tesis va a contracorriente de la mayor parte de la bibliografía especializada, creo conveniente insistir en las razones que asisten a quienes hablan de la linealidad de la biografía de Poveda. Desde este punto, en diálogo crítico, intentaré aportar la documentación -extraída del hasta el momento único volumen de sus Obras - que justifica, en cambio, mi postura. Lo hago en tres apartados: las biografías povedanas: la conflictiva novedad de un mensaje espiritual y pedagógico; entre Guadix y Covadonga, la acción de la Institución Libre de Enseñanza y la confrontación con ella, de Covadonga a Jaén: desencuentros y acuerdos.

\section{Las biografías povedanas: la conflictiva novedad de un mensaje espiritual y pedagógico}

De entrada, anticipo que, a mi juicio, la pregunta decisiva consiste en responder por qué se produce en el pensamiento povedano el «cambio» del sujeto sobre el que se reflexiona -del educando al educador- y no el señalar que tanto da, pues lo que importa es que la finalidad continúa siendo la misma. Resulta de la máxima trascendencia esta variación para acercarse a la biografía de Poveda, pues sitúa su identidad en lo que Paul Ricoeur denomina la dialéctica concreta de la ipseidad y la mismidad. Hasta ahora, ha prevalecido una actitud que primaba el segundo término, entendida como continuidad ininterrumpida del «carácter» povedano. Pero, como dice Ricoeur, aparte del carácter, hay otro modelo de permanencia en el tiempo: la palabra mantenida en la fidelidad a la palabra dada ${ }^{37}$. Es decir, cambiando las circunstancias, Poveda no sigue siendo sin más el mismo, sino que se esfuerza por perseverar en una identidad cristiana comprometida con su realidad histórica, más que con un modo concreto de vehicular tal compromiso.

37 Paul Ricoeur, Sí mismo como otro, Madrid, Siglo XXI, 1996, p. 118. 
En este sentido, uno de los problemas principales a los que han tenido que hacer frente los biógrafos ha sido la periodización de su vida. Entre las primeras biografías, escritas por contemporáneos y conocidos del protagonista, interesaba más remarcar cuál era el ideal pedagógico que animó su vida entera culminada en el martirio, que describir la evolución histórica del personaje. Descontando la entusiástica hagiografía de Agustín Serrano de Haro, cabe resaltar la biografía del carmelita Silverio de Santa Teresa, dentro también del tono habitual de la inmediata posguerra española, aunque moderado por un esfuerzo de cierta objetividad narrativa ${ }^{38}$. En esta línea, donde lo importante es presentar el mensaje de Poveda utilizando como pretexto la trama cronológica, sobresale, sin embargo, el estudio del jesuita Domenico Mondrone, cuyo título original en italiano era muy significativo: Un prete scomodo ${ }^{39}$.

A partir de los años 80, se ha puesto en marcha la empresa de mayor calado en este ámbito: los Cuadernos biográficos de Pedro Poveda, a cargo de Flavia Paz Velázquez. Hasta el momento han aparecido ocho cuadernos, que comprenden desde el nacimiento del fundador de la Institución Teresiana hasta la aprobación pontificia de ésta como Pía Unión Primaria (1924). Faltan, por tanto, el periodo más tenso y, a la vez, más fecundo de la historia reciente de España, especialmente en el campo ideológico y educativo: el que va de la Dictadura de Primo de Rivera al estallido de la Guerra Civil ${ }^{40}$. Provisionalmente, este hueco, por lo que se refiere a Poveda, queda cubierto por las presentaciones a estos años incluidas en el primer volumen de las Obras $^{41}$.

Escritos con gran rigor y una documentación abrumadora, los Cuadernos de Velázquez, más que una biografía propiamente dicha, constituyen un volumen propedéutico, que, en ocasiones, sigue casi diariamente los acontecimientos de la vida del protagonista. Especialmente incisivos, en cuanto a interpretación,

38 Agustín Serrano de Haro, La estela de un apóstol, Madrid, Publicaciones de la Institución Teresiana, 1942. Esta obra fue ampliada posteriormente por el mismo autor con el título de Una figura del pensamiento español, Don Pedro Poveda Castroverde: diseño biográfico, Madrid, Escuela Española, 1974. El mismo año que la primera se publicó la de Silverio de SANTA Teresa, Vida de Don Pedro Poveda, Fundador de la Institución Teresiana, Madrid, Publicaciones de la Institución Teresiana, 1942.

39 Domenico Mondrone, Un prete scomodo. Don Pietro Poveda Castroverde, fondatore dell'Istituzione Teresiana, Roma, La Civiltà Cattolica, 1961 (la traducción castellana, aparecida el año de la clausura del Concilio Vaticano II, se titula, asépticamente, El P. Poveda, Madrid, Ediciones Paulinas, 1965).

40 Por orden, se titulan estos cuadernos de Flavia Paz VelázQuez, Raíces linarenses, En los cerros de Guadix, Meditación de Covadonga, Proyectos pedagógicos, Las Academias, Una Institución se abre camino, Sal de tu tierra, Pedro Poveda en Madrid. Arraigo y expansión de una idea, Madrid, Narcea, 1986-2003.

41 Dolores Gómez Molleda, «Escritos 1925-1930. Presentación», en Pedro PovedA, Obras, pp. 657-678; «Escritos 1931-1936», ibid., pp. 938-964.

Hispania Sacra, LIX

120, julio-diciembre 2007, 707-740, ISSN: 0018-215-X 
son los volúmenes titulados Meditación de Covadonga y Proyectos pedagógi$\cos$, dedicados a la etapa asturiana.

Ahora bien, la concepción monumental del conjunto y su ejecución plantea una serie de problemas, de los cuales simplemente menciono los dos más importantes, uno de tipo externo y otro más propiamente formal. Entre el primer y el último cuaderno han transcurrido diecisiete años. El ritmo de publicación no ha sido, en cambio, acompasado: los cuatro primeros volúmenes salieron a la luz entre 1986 y 1987; hubo un paréntesis de diez años, tras los cuales salieron otros dos cuadernos (1996-1997), los cuales dieron paso a otro interregno de cinco años, antes de ser editados los dos últimos (2002-2003). Como es lógico, esta falta de continuidad, comprensible por la envergadura de la obra, realizada, además, por una sola persona, hace más difícil, si cabe, su recepción fuera del ámbito de la Institución Teresiana. Junto a esta realidad, téngase en cuenta también que, sin todavía haber sido concluida, la obra comprende ya más de mil quinientas páginas, elaboradas con un detalle y una precisión admirables, pero que dificultan una visión global concreta y abarcable del personaje.

Flavia Paz Velázquez muestra extraordinaria sensibilidad ante el esfuerzo de Poveda por vivir sincronizado con un mundo moderno que, pese a las inercias españolas, se caracteriza por la aceleración de los procesos sociales, económicos e ideológicos. Entre los muchos méritos de sus Cuadernos me interesa en este momento, pues, destacar la flexibilidad a la hora de caracterizar las diversas etapas, intentando tejer su historia personal con la historia política y social de su época.

Habitualmente, se han utilizado tres criterios: el geográfico -lugares en que Poveda residió-; enlazando con éste, el institucional -el desarrollo de las Academias-; y, por último, el periodológico habitual en la historiografía. Velázquez opta básicamente por el primero: Linares (1874-1894); Guadix (1894-1905); Covadonga (1906-1913); Jaén (1913-1921); Madrid (1921-1936). A partir de Covadonga, introduce subdivisiones en cada periodo que corresponden, por un lado, al desarrollo de su Obra -con un juego dialéctico de preparación y madurez de los objetivos de cada etapa- y, por otro, a lo que fue una constante de la vida de Poveda: la conflictividad que suscitaban sus iniciativas, pese a su denodado esfuerzo por rehuir el enfrentamiento. Así, por ejemplo, la etapa de Jaén, a la que Flavia Paz Velázquez dedica tres volúmenes, gira en torno a la fecha de aprobación diocesana de la naciente Institución (1917), desde la cual se contempla el sentido de las contradicciones personales y el acoso que las Academias sufren por parte de personas cercanas a la Institución Libre de Enseñanza ${ }^{42}$.

\footnotetext{
${ }^{4}$ Flavio Paz VelázQuez, Una Institución se abre camino, Madrid, Narcea, 1997, pp. 55-82 especialmente.
} 
Como he dicho, estos graves problemas suelen explicarse por cuanto «la cuestión que tensaba los ánimos de católicos y laicistas» era «regenerar la escuelas en sentido neutro o laico o regenerarla en sentido católico» ${ }^{43}$. Por tanto, Poveda, regeneracionista como buen católico social, tenía por misión la promoción social por medio de la educación y la cultura. Este enfoque era ya palpable en la biografía de Mercedes Gómez del Manzano que primaba, por encima de todo, el aspecto institucional: Guadix y Covadonga era la preparación de una Obra social («urgido por el Reino») que acopia toda su energía durante el periodo que media entre su fundación y las aprobaciones diocesana y pontificia (1911-1917: «urgido por el Espíritu»; 1917-1924: «urgido por la humildad»), hasta desplegarse en su sentido de diálogo y apertura a la transformación evangélica del mundo que le rodea (1924-1936: «urgido por la mansedumbre») ${ }^{44}$.

Dolores Gómez Molleda, que en una antología de escritos había preferido combinar, con gran apertura, el criterio geográfico-institucional en función de la redacción de las principales obras, ha optado en la edición del primer volumen de las Obras por otro eminentemente institucional, sosteniéndolo sobre la perspectiva periodológica del regeneracionismo. Aquí distingue cinco grandes grupos: 1) escritos de tipo estrictamente espiritual (La voz del Amado, Visita a la Santina), a los que siguen las primeras preocupaciones pedagógicas (En provecho del alma, Para los niños, Para los jóvenes) (1906-1910); 2) escritos vinculados a la puesta en marcha de las Academias, que sirven de base del espíritu laical teresiano, hasta la primera aprobación diocesana (Consejos, Avisos espirituales de Santa Teresa, «Verdadero humanismo. Toda de Dios», «La Obra es Jesucristo» (1911-1917); 3) escritos relacionados con la singular fisonomía carismática y jurídica de la Institución Teresiana (sobre todo, Jesús, Maestro de oración) (1917-1924); 4) escritos que muestran consolidación de la obra y el planteamiento de nuevas iniciativas a partir de la Asamblea general de 1928 (1925-1930); 5) escritos que reflejan las tensiones y las posibilidades de evangelización de una época convulsa (1931-1936)

La tesis básica que se deduce de esta perspectiva historiográfica es la adscripción de Poveda a un catolicismo social que hace de la educación un instru-

\footnotetext{
43 Dolores Gómez MolledA, «Escritos 1918-1924. Presentación», en Pedro PovedA, Obras, p. 364.

${ }^{44}$ Mercedes Gómez del Manzano, Pedro Poveda. Dinamismo profético, Madrid, Narcea, 1991 (he entrecomillados los subtítulos de cada capítulo).

${ }^{45}$ En la antología, Gómez Molleda había hecho una división en seis partes, de las cuales la primera y las dos últimas coinciden con la que presenta en las Obras. Las otras tres las divide en cuatro: proyectos pedagógicos y fundación de las tres primeras Academias (Oviedo, Linares y Jaén) (1911-1914); periodo de Jaén (1915-1919); y el impulso final hacia la aprobación a partir de la composición de las consideraciones que quedarían recogidas en la obra Jesús, Maestro de oración (1920) (Pedro PovedA, Amigos fuertes de Dios, Madrid, Narcea, 1993 (4a ed., 2005).
}

Hispania Sacra, LIX

120, julio-diciembre 2007, 707-740, ISSN: 0018-215-X 
mento de regeneración popular desde una perspectiva que podría calificarse de progresista, siempre desde dentro no sólo de la ortodoxia doctrinal sino también de la ortopraxis católica de su época. En este sentido, podría decirse que la presencia cristiana en la escuela pública tendría que ver sobre todo con la preocupación por las clases sociales populares que no podían acceder a la enseñanza privada. Históricamente, asume el hecho de que la Dictadura de Primo de Rivera buscó una fuente de legitimación en la recuperación del programa regeneracionista.

Insisto que no seré quien discuta que el compromiso social de Poveda constituyó el motor de su vida. Ángeles Galino es tajante al respecto desde la primera página de su prólogo a la antología clásica del sacerdote andaluz: «Quien desconozca la denodada actuación social del Padre Poveda se condena a no comprender enteramente el significado de sus puntos de vista sobre educación». Pero, previamente, con saludable prudencia, afirmaba que a quien concluyera que su pensamiento y su obra respondían a una urgencia de regeneración social «seguramente no habría nada que objetar» ${ }^{46}$.

Lo que me gustaría sostener es que, sin nada que objetar a la imagen regeneracionista, la riqueza de su pensamiento y su obra excede este ámbito para ingresar de lleno en la reflexión contemporánea sobre el proceso de modernización de la sociedad española a través de una política educativa dirigida estatalmente. La escuela pública, cuyo ideal en la II República será el de la escuela única, no es una escuela para los pobres sino un instrumento privilegiado para transformar el modelo de sociedad. Desde luego, se concibió esta escuela como el lugar decisivo para el progreso social y moral de la nación, en dirección a una mayor justicia; pero tal progreso sólo sería posible no sólo secularizándola plenamente sino considerándola incompatible con cualquier modo de confesionalidad que, en España, quería decir catolicismo.

La originalidad del pensamiento povedano y la incomodidad que podían suscitar en ambos bandos sus ideas procedían precisamente de haber captado desde los tiempos de Covadonga esta antinomia que él, como cristiano, se niega a aceptar como insoluble. Por ello, decir que Poveda tuvo como meta la promoción social por medio de la educación y la cultura es cierto, pero no agota la singularidad de su propuesta. Desde el Ensayo de proyectos pedagógicos propone la escuela pública no como un medio entre otros para alcanzar el fin común sino como un objetivo central al que supeditar todas las otras estrategias: «primero, formar, según el espíritu cristiano y ajustándose a los mejores métodos pedagógicos, un cuerpo de profesores de primera enseñanza, a quienes pre-

46 Ángeles GaLINo, op.cit., p. 19. 
sentará anualmente a oposiciones a fin de obtener el mayor número de plazas en las oposiciones a escuelas públicas» ${ }^{47}$.

\section{Entre Guadix y Covadonga, la acción de la Institución Libre de Enseñanza}

Giner de los Ríos, como buen republicano liberal, había mostrado a menudo desconfianza ante las intervenciones del Estado. Según Yvonne Turin, a diferencia de los liberales, que defendían la necesidad de la misión docente del Estado para impedir que la Iglesia se convirtiese en dueña de la educación, los republicanos sostenían que enseñar era un derecho de la sociedad, tratando de evitar así también la dictadura del Estado48. En 1876 la propia ILE se había fundado esperando convertirse en una Universidad Libre. Libertad de cátedra y autonomía universitaria habían constituido inicialmente, pues, los dos ejes en que cimentar un proceso de modernización que implicaba la secularización de la sociedad española.

Como Dolores Gómez Molleda estudió en profundidad en Los reformadores españoles, los discípulos de Giner habían obtenido, a principios del siglo XX, su autorización para intervenir en la vida política con el objetivo de poder llevar a efecto su programa modernizador. De este modo, la fecha de 1907 supuso un punto de inflexión en la trayectoria de la ILE. En aquel año se creó la Junta para la Ampliación de Estudios; en 1909 se inauguró la Escuela Superior de Magisterio; en 1910, se abrió la Residencia de Estudiantes y se abrió el Centro de Estudios Históricos; en 1911, Rafael Altamira, preeminente catedrático del círculo institucionista de la Universidad de Oviedo, fue nombrado para el cargo de primer Director General de Enseñanza Primaria; en 1915, se puso en marcha la Residencia de Señoritas; en 1917, se creó el Instituto-Escuela...

Coherentes con una perspectiva republicana de que «la obra más sólida y más importante del Estado debe ser una obra de organización, de creación. En ese orden, la acción oficial es irremplazable para la instrucción pública» ${ }^{49}$, todas estas iniciativas, promovidas desde las estructuras estatales, querían mantener un perfil administrativo y técnico que las pusiesen a salvo de los vaivenes políticos de los gobiernos de uno y otro signo. Su puesta en marcha, que obedecía a un indudable cambio de estrategia de los miembros vinculados a la ILE, pretendía dotar de contenido el programa regeneracionista finisecular, al que la ILE había aportado su ya larga experiencia. Según Otero Urtaza, incluso el pro-

\footnotetext{
47 Ibid., p. 111.

48 Ivonne Turin, La educación y la escuela en España de 1874 a 1902, Madrid, Aguilar, 1967, pp. 144-170

49 Ibid., p. 162.
}

Hispania Sacra, LIX

120, julio-diciembre 2007, 707-740, ISSN: 0018-215-X 
yecto educativo que Joaquín Costa presentó en la Liga Nacional de Productores en 1898, suscitando controversia, fue escrito por Manuel Cossío y anotado por Giner $^{50}$. La creación en 1901 de un Ministerio de Instrucción Pública independiente, al margen del Ministerio de Fomento del que había venido dependiendo orgánicamente, reflejaba, por tanto, que la preocupación educativa pasaba de ser un problema social al que se debía dar una solución a convertirse en un problema de Estado.

Inflexión, pues, en el modo de proceder de la ILE que en nada contradecía su trayectoria anterior sino que la profundizaba y la redirigía dentro de un horizonte más amplio de proyección social, en el cual siempre se había movido, alentada por el organicismo krausista, como lo demuestra su preocupación por la educación de los obreros, a través, por ejemplo, de la Extensión Universitaria creada en Oviedo (1899).

Entretanto, un joven y desconocido sacerdote de Guadix funda unas escuelas para los cueveros, dentro de las líneas del catolicismo social, bajo el magisterio de Manjón. El problema estriba en que ese sacerdote, Pedro Poveda, las abandona en 1905. No se marcha de Guadix por voluntad propia. No le queda otro remedio, visto el acoso eclesiástico al que es sometido entre junio de 1904 y febrero de 1905, que huir de Guadix, desatando una auténtica tormenta eclesiástica y social, que culmina en graves disturbios sociales, incluido un intento de asalto al palacio episcopal, a los que es, por otra parte, completamente ajeno ${ }^{51}$. Las referencias existentes en los Diarios de Manjón insinúan que sufrió crisis nerviosas ${ }^{52}$. Pasa cerca de tres meses sin poder celebrar. Su obispo llega a enviar una carta al Nuncio denunciando a su antiguo familiar. Aunque las biografías no han aportado hasta este momento más que rumores parece que, aparte de insinuaciones calumniosas sobre su conducta moral, el grueso de la acusación se centraba en que, como director de las escuelas, favorecía un supuesto ambiente laico ${ }^{53}$. Acusación, por otra parte, que podía apoyarse en el hecho de que su familia, de tradición republicana por el lado paterno, le había puesto en contacto con Gonzalo de Figueroa, conde de Arcentales, Patrono de las Escuelas del Sagrado Corazón y hermano del Conde de Romanones, Ministro de Instrucción Pública, cuya actuación había suscitado fuertes reacciones en el campo católico. Por todo ello, se antoja una explicación prudentemente piadosa decir, como hace Vicente Cárcel Ortí, que

\footnotetext{
50 Eugenio Otero URTAZA, op. cit., p. 225.

51 Flavio Paz VelázQuez, En los cerros de Guadix, Madrid, Narcea, 1986. pp. 238-263.

52 Andrés Manjón, Diario. 1895-1923, ed. de J. M. Prellezuelo, Madrid, BAC, 2003, pp. 341-342.

53 Flavia Paz VelázQuez, En los cerros de Guadix, p. 268. Sería deseable que pudiesen exhumarse, después de cien años, este tipo de documentos para conocer los métodos de control y vigilancia eclesiásticos y las prácticas punitivas que de ellos se derivaban.
} 
«ante las importantes dificultades que encontró para llevar adelante su proyecto, en 1905 abandonó esta ciudad» ${ }^{54}$.

Lo cierto es que, tras un par de años dedicados en Covadonga a escritos eminentemente espirituales, comienza, si no a recobrar, sí a manifestar claramente de nuevo su vocación por las cuestiones pedagógicas, en un sentido que supone un notable avance en su comprensión del fenómeno educativo. Aunque todavía recoge con interés las iniciativas que le plantean de tinte social, con la esperanza que no llegó a realizarse de fundar escuelas gratuitas para los niños pobres en Cantarranas, ya en 1908 solicita a su obispo, con la consiguiente negativa, el poder obtener el título de maestro nacional. Es el momento de las condenas papales contra el modernismo que se traducen en normas estrictas vetando a los eclesiásticos acceder a estudios civiles. En todo caso, a partir de 1909 se multiplican sus esfuerzos en el campo de la enseñanza, ya no privada sino con la vista puesta en la enseñanza oficial y, más concretamente, en la formación de los futuros maestros.

En octubre de 1910 envía a su mecenas Gonzalo de Figueroa un memorando titulado «Estudio y presupuesto para la fundación de una Residencia de Estudiantes», cuyo objetivo era proporcionar tanto alojamiento como un ambiente de estudio a los maestros que se preparasen a concursar a puestos oficiales. Aquel mismo curso abría sus puertas la Residencia de Estudiantes dirigida por Jiménez Fraud.

Podría argüirse, no obstante, que una iniciativa como la suya tenía un antecedente en la preocupación de Manjón por formar sus propios maestros, así como en los esfuerzos de éste, desde al menos finales del siglo XIX, por fundar una Escuela Normal Libre ${ }^{55}$. Al final logrará fundar en 1905 el Seminario de Maestros de Granada. Allí formará a los maestros ave-marianos ${ }^{56}$. Pero Poveda, cuando publica el Ensayo de proyectos pedagógicos (1911), no pretende proponer un nuevo modelo de escuela, sino crear una Institución Católica de Enseñanza que sea capaz de agrupar a todas las fuerzas católicas y contrarrestar la influencia de los «enemigos» de la Iglesia (se sobreentiende que los partidarios de la escuela neutra) en el mismo ámbito en que ellos están llevando a cabo su acción: la escuela pública que se ha empezado a construir ya como una escuela

54 Vicente CÁRCEl ORTí, Diccionario de sacerdotes diocesanos españoles, Madrid, BAC, 2006, p. 919

55 «Rufino Blanco, chico listo, puesto por el ministro para cuidar de las Normales de maestros, me promete, en nombre de aquél, la libre facultad de fundar escuelas libres Normales», Andrés. MANJóN, Diario, op. cit., p. 175).

56 Sobre la génesis y evolución histórica de este Seminario de Maestros, véase el documentado estudio de Andrés Pama Valenzuela, Avemarianos. Identidad y memoria. En el Centenario del Seminario de Maestros del Ave-María (1905-2005), Granada, Imprenta-Editorial Ave-María, 2005.

Hispania Sacra, LIX

120, julio-diciembre 2007, 707-740, ISSN: 0018-215-X 
nacional. De ahí, las reticencias que encuentra a su proyecto por parte de los principales prohombres de la educación católica (Manuel González, Rufino Blanco, Ramón Ruiz Amado y, de modo especialmente áspero, Andrés Manjón $)^{57}$.

La pregunta clave gira, por tanto, en torno a este dato: ¿por qué la propuesta de Poveda de unir fuerzas -común en las proclamas oficiales de la, por otra parte, dividida opinión católica- suscita, para su decepción, tan poco entusiasmo, como queda atestiguado por el conjunto de cartas que transcribió en la manuscrita Historia de los folletos? ${ }^{58}$. La explicación habitual ha señalado que los proyectos, generosos y optimistas, no correspondían con la realidad desgarrada del catolicismo español. Innovadores desde un punto de vista teórico, habrían malgastado en la práctica las contrapuestas energías de la acción educativa en el campo católico. En consecuencia, su autor habría aplicado su máxima de «comenzar haciendo» y habría puesta en marcha las Academias, que, inauguradoras de un nuevo carisma eclesial, representaban, en primer lugar, un nuevo modo de educar en clave cristiana de acuerdo con la preocupación social que había animado a su fundador desde Guadix ${ }^{59}$.

\section{La confrontación con la ILE, de Covadonga a Jaén: desencuentros y acuerdos.}

Este planteamiento tiene muchas ventajas. Ayuda a situar, sobre todo, al «incomprendido» Poveda en la vanguardia de los esfuerzos sociales, comprometido con la transformación de las condiciones de pobreza a través de la educación. Ahora bien, pasa por alto una serie de hechos. Él no estaba interesado en fundar solamente establecimientos de enseñanza ni de formar a las futuras maestras de centros privados. Atento a la legislación, quiso desde el primer momento que sus Academias mantuviesen una estrecha colaboración con las Escuelas Normales oficiales, basándose en un estilo cristiano que testimoniase que no existía contradicción entre la fe y la ciencia, o, lo que es lo mismo, que

57 « QQuiere V. tomar parte en ese movimiento, descendiendo de las altas torres del deseo y ensueño a las impuras y laboriosas realidades del mundo de los hechos? Hablaremos. ¿Pretende montar en aeroplano al magisterio, sirviéndole de piloto? Vuele, vuele primero, y no vuelque comprometiendo ideas, instituciones y personas no hechas al vuelo» (Carta de Andrés Manjón a Pedro Poveda, datada el 11 de septiembre de 1912, en Historia de los folletos, p. 33).

58 Actualmente esta Historia de los folletos, compilada autógrafamente en 1913, se conserva en el AHIT. Utilizo ampliamente esta fuente de primera mano sobre la recepción de las principales obras en Modernidad y pedagogía en Pedro Poveda...

59 Rafael M ${ }^{\text {a }}$ SANZ DE DIEGo, «Pedro Poveda, lector de Razón y Fe en Covadonga», en Pedro PoveDA, Volumen-homenaje. Cincuentenario 1936-1986, Madrid, Narcea, 1986, pp. 159-160. 
el cristianismo no era ajeno ni antagónico a los más modernos métodos pedagógicos en que se cifraba la posibilidad de transformar las sociedades en espacios más justos y solidarios. De acuerdo con los planes elaborados por el ministro Julio Burell, era posible agregar Residencias a aquéllas, en donde los estudiantes oficiales pudiesen continuar sumergidos en la atmósfera de renovación a las que se les quería someter. En 1914 el propio Poveda se adelanta a los institucionistas y funda en Madrid una Residencia para universitarias.

Esta actitud abierta a las novedades intelectuales, en las cuales desea intervenir como protagonista con voz propia, incide además en su concepción de la acción social católica. He aquí, como hemos dicho, otra de las causas por la cual sus proyectos pedagógicos fueron fríamente recibidos. Recién dadas en 1910 las primeras instrucciones para poner en marcha la Acción Católica española, propone una Institución Católica de Enseñanza que, junto con la estatalización de la enseñanza, aborda, en la segunda edición de los Proyectos pedagógicos (1912), el problema del asociacionismo del magisterio como el embrión de una acción católica coordinada, pero no uniformadora, más próxima a un modelo en red que vertical. En suma, una acción católica bajo la dirección de los obispos y administrada por los técnicos. Como hemos dicho, desde una postura no sólo muy crítica sino hasta beligerante con los fines, percibe, sin embargo, la fecundidad de las tácticas paraestatales practicadas por los institucionistas. En este sentido, cabe preguntarse si realmente sus proyectos se avanzaban a su época, como sostienen quienes justifican el fracaso de su proyectada Institución Católica de Enseñanza, o si fueron sus interlocutores los que tenían el reloj retrasado ${ }^{60}$.

Ciertamente, dado el nivel eclesiástico de la época, con divisiones internas crónicas entre los católicos, las cuales impacientaban hasta en Roma, los proyectos povedanos podían parecer utópicos, pero es legítimo preguntarse si, más bien, la pastoral educativa de aquella época, convulsionada por la Semana Trágica y por los intereses de las congregaciones religiosas que se consideraban amenazadas por el supuesto laicismo de Estado, estaban realmente citados con el momento ${ }^{61}$. Que «la «acción católica en lo pedagógico» de que hablaba Pe-

60 «Su lenguaje -«acción católica», «acción social» de los seglares- era el indicado. Pero la cita con el momento no era la apropiada» (Dolores GómEZ MolledA, «Estudio introductorio», op. cit., p. LIII).

${ }^{61}$ Recuérdense la encíclica Cum multa de León XIII (1882), así como el Breve del mismo Pontífice Inter catholicos Hispaniae (1906) animando a la superación de las divisiones entre católicos (Vicente Cárcel Ortí, «Los obispos españoles y la división de los católicos. La encuesta del nuncio Rampolla», Analecta Sacra Tarraconense 55-56 (1982-1983): 107-207). Una visión del catolicismo español de las dos primeras décadas del siglo XX, cercana a los hechos y desde Roma, ha sido publicada también por Vicente Cárcel Ortí, «Instrucciones del Cardenal Gasparri a Tedeschini», Revista Española de Derecho Canónico 48.131 (1991): 455-482.

Hispania Sacra, LIX

120, julio-diciembre 2007, 707-740, ISSN: 0018-215-X 
dro Poveda, suscitaba, pues, fundadas incertidumbres en cuanto a sus posibilidades de realización ${ }^{62}$ no desmerece, a mi juicio, la reflexión povedana, por más que explique las causas de su «fracaso» en la práctica. Sólo vista en relación con el avance del proceso de secularización que se libraba en torno a la escuela, no sólo en sus aspectos negativos sino principalmente en los positivos, en lo que hace referencia a métodos, organización y, sobre todo, en cuanto a la mejora científica y profesional de la formación de los educadores, es posible advertir que Poveda no era en absoluto un arbitrista iluso, como llegó a considerarlo el propio Manjón, sino un pensador católico capaz de articular un programa que, desde la propia tradición católica, intentaba asumir en clave cristiana las más sobresalientes aportaciones de sus adversarios, en aquel momento representados por la ILE.

Su compromiso social adquiere, bajo esta luz, una nueva tonalidad, dado que en sus Academias aquél tuvo siempre un lugar destacado. Por ejemplo, aceptó en Jaén la dirección del Centro Obrero Catequístico al que enviaba a sus normalistas para que, dando clases, entrasen en contacto con su futuro profesional como maestras. Como dice Flavia Paz Velázquez, «de acuerdo con la idea de Poveda, en la Academia se forma a las futuras maestras para cumplir la función social de «promocionar las clases proletarias por la educación de la persona»»63. Pero esta finalidad perseguía un objetivo clave: asumir la estatalización de la enseñanza desde el interior del proceso secularizador, haciéndose presente e influyendo en su marcha. De la mera acción social pasa a plantar batalla en el centro del debate ideológico de la época: la neutralidad o no de la escuela pública.

En este sentido, especialmente ilustrativos son sus problemas a partir de 1915 en Jaén, con personas cercanas al mundo de la Institución Libre de Enseñanza $^{64}$. Este choque, en que Luis de Zulueta, profesor de la Escuela de Magisterio y posteriormente Ministro de Estado de la II República, se empleará a fondo, no le hará ganar, de todos modos, un especial aprecio entre los sectores católicos. Tras el alivio de la aprobación diocesana (1917) en Jaén de la naciente Institución, Poveda se ve amargamente sorprendido por la decisión del administrador apostólico de la diócesis de recomendarle que se retire del Directorio, petición que se hará efectiva definitivamente en 1922.

En todo caso, del grave conflicto que tiene como escenario la Normal de Jaén, en la que se quería poner en práctica la colaboración de los Internados

\footnotetext{
62 Dolores Gómez MolledA, ibid., p. LVII.

${ }^{63}$ Flavia Paz Velázquez, Las Academias (Cuadernos Biográficos Pedro Poveda 5), Madrid, Narcea, 1996, p. 169.

${ }^{64}$ Una exposición detallada de las circunstancias en que se produjeron estos enfrentamientos puede leerse en Flavia Paz Velázquez, Una Institución se abre camino (Cuadernos Biográficos Pedro Poveda 6), Madrid, Narcea, 1997, pp. 55-110.
} 
agregados, cabe resaltar sus antecedentes y su fin. En 1915, José Castillejo propone a instancias de María de Maeztu, directora de la recién inaugurada Residencia de Señoritas, a Mariana Ruiz Valecillo el cargo de ayudante de dirección. En ese momento Ruiz Valecillo ejerce como directora de la Residencia para universitarias fundada por Poveda. Para facilitar su decisión, recibe la sugerencia de fusionar ambas residencias -mejor dicho, de ser absorbido el centro teresiano en el nuevo organismo-. Rufino Blanco, destacado profesor católico de la Escuela Superior de Magisterio, aconseja también la fusión, pero Poveda, aun siendo consciente de lo atractiva de la propuesta para su colaboradora, duda sobre la conveniencia de aceptar, dado que, aunque persiguen los mismos objetivos pedagógicos, los fines institucionistas y los católicos de la Obra teresiana divergen. Finalmente, se opta por declinar la invitación ${ }^{65}$.

No obstante esta decisión basada tanto en motivos de principios como en razones estratégicas -acompañada también de una negativa a fusionarse con las religiosas del Sagrado Corazón-, Poveda anima al mismo tiempo a Josefa Segovia, entonces directora de la Academia de Jaén, a mantener una estrecha relación profesional con Alfonso Barea, el nuevo inspector provincial, de simpatías institucionistas. Aunque pronto las tensiones en la Normal de Jaén los coloquen en bandos antagónicos, esta actitud revela, a juicio de F. P. Velázquez, una constante en la trayectoria del fundador de la Institución Teresiana: «el respeto hacia las personas que simpatizan con la ideología institucionista y el deseo de establecer con ellas una relación cordial y armónica está vivo en Poveda desde siempre; desde su juventud, puede decirse que constituye uno de sus propósitos más firmes» 66 .

Esta afirmación viene apoyada por el hecho biográfico de que el padre de Poveda hizo gestiones para enviar a su hijo adolescente al Colegio Internacional, fundado por Salmerón, e integrado ya en aquel momento en la ILE; también por la relación con primos educados en el centro gineriano. Aparte de estas circunstancias familiares, incluso en la época de mayor confrontación con personas vinculadas al institucionismo, muestra una disponibilidad al diálogo no rara e infrecuente sino excepcional en el catolicismo de la época, para quien la ILE simbolizaba el enemigo irreconciliable. Cuando el objetivo parecía la extinción de la Obra teresiana, tuvo la valentía de reunirse, acompañado de Rufino Blanco y de José Rogerio Sánchez, con Luis de Zulueta, Adolfo Buylla y Gumersindo de Azcárate, a fin de llegar a un acuerdo que pusiese término a los enfrentamientos de Jaén, con la separación entre Normal e Internado y el respeto pleno a los derechos de las alumnas de éste último ${ }^{67}$.

\footnotetext{
65 Ibid., pp. 30-34.

66 Ibid., p. 39.

${ }^{67}$ Ibid., pp. 89-91.
}

Hispania Sacra, LIX

120, julio-diciembre 2007, 707-740, ISSN: 0018-215-X 
Tras esta aparente tregua, los conflictos con sectores laicistas reaparecerán en diversos momentos, especialmente a consecuencia de la política educativa de la II República, en concreto durante el mandato de Rodolfo Llopis como Director General de Primera Enseñanza. Es precisamente en las raíces de esta confrontación donde es posible advertir y resaltar la modernidad -y la diferencia con respecto a otras iniciativas católica de la época- de la propuesta povedana. Este choque no se produce tan sólo entre dos visiones de mundo contrapuestas y excluyentes que defienden, correlativamente, dos modelos de sociedad apoyados en dos modelos de escuela: la visión cristiana que defiende la enseñanza «libre» frente a la visión laica que avanza hacia la escuela «única» que, por definición, ha de ser pública.

De hecho, el enfrentamiento tiene lugar en el interior mismo de esta última escuela que querría verse libre de cualquier dogmatismo religioso. Queda planteado el alcance de la actividad pública de los cristianos, así como se anticipan los fundamentos de una laicidad muy conflictiva en el seno de una incipiente sociedad democrática. Como bien dice Gómez Molleda, la apuesta que Poveda renueva desde 1931 consistía en mostrar que «modernizar la enseñanza, introducir nuevos métodos, proponer objetivos comunes, proyectar instituciones renovadas y señalar metas era posible sin renunciar a la orientación cristiana de la educación» ${ }^{68}$. Este debate, que marca en España su precaria incorporación al pensamiento político europeo, no es simplemente regeneracionista sino que, excediendo este marco, es ya moderno. No se trataba tan sólo de paliar y resolver situaciones de injusticia y atraso por medio de la cultura y la educación, sino de establecer los mecanismos y los recursos que hicieran posible el llevar a cabo efectivamente una acción global de transformación social, concebida en aquel momento como una acción estatal-nacional cuya instrumento privilegiado era la educación.

\section{LAS PARADOJAS POVEDANAS: HISTORIA CIVIL O/Y HISTORIA RELIGIOSA}

Sin duda, sería reductor olvidar la multiplicidad de iniciativas que propone y secunda Poveda en el campo de la educación confesional a lo largo de toda su biografía, y, en especial, a lo largo de los años veinte y treinta: la Federación de Amigos de la Enseñanza, la Liga de Orientación y Cultura, la no nata Universidad Católica promovida por Herrera Oria a imagen de la Università Cattolica de Milán... En todo caso, siempre concibió su Obra como un instrumento al servicio de la Iglesia, arraigada en una espiritualidad cristiana radical, de fuentes te-

\footnotetext{
${ }^{68}$ Dolores Gómez MolledA, «Estudio introductorio», op. cit., p. CXXXVIII.
} 
resianas, y caracterizada por una actitud de diálogo y de moderación que contrastaba con las posiciones cada vez más polarizadas de la sociedad española.

No es por ello extraño que su figura, como hemos dicho al principio, permanezca en un claroscuro, en parte porque la historiografía «civil» ha colocado normalmente todas las obras de la Iglesia como opuestas, por principio, al proceso de nacionalización, vinculado éste a la secularidad y al progreso social y científico a través de la escuela. Repito: la escuela republicana era considerada por sus partidarios un instrumento de regeneración y de arraigo y difusión de los ideales democráticos. Lucha contra el analfabetismo y libertad política eran vistos como antagónicos de los intereses económicos e ideológicos que animaban la reclamación del predominio en el terreno educativo por parte de la Iglesia ${ }^{69}$.

Aunque Poveda, desde una auténtica postura cristiana, veía con dolor los excesos cometidos por la legislación republicana, dejando constancia por escrito de ello reiteradamente, no puede negarse, a juzgar por los estudios de sus seguidoras, que su preocupación regeneracionista coincidía con la republicana, sin plantear dudas sobre la aceptación de la legalidad de las decisiones de la República.

Es comprensible, entonces, que considerase su Obra como «providencial», en la medida que, al no ser una congregación religiosa sino una Pía Unión, no estaba sometida a la ley que prohibía la enseñanza de éstas. En un sentido amplio, este carácter «providencial» no era singular. Aquella medida extrema en la «guerra escolar» «resultó claramente contraproducente al facilitar argumentos a sus enemigos y no evitar que la Iglesia católica mantuviese un total de 1500 colegios, escuelas e internados a través de gestores interpuestos ${ }^{70}$. Podría decirse así que las Residencias teresianas formaban parte de este entramado de asociaciones instrumentales que, a juicio de Claret Miranda, «se alejaban del camino democrático. A partir del 18 de julio de 1936, los golpistas podrán contar con la experiencia, el personal y el apoyo de estas redes» ${ }^{71}$.

Dicho así, como señalo, la singularidad del proyecto povedano queda diluida. Por más que se insista en su compromiso social (que también mantenían hombres de la incipiente Democracia Cristiana de los años veinte como Herrera Oria o Severino Aznar), la especificidad del programa povedano consistía, no obstante, en aquel objetivo que marcaba en 1911: la presencia cristiana en la escuela pública. Y este objetivo no puede entenderse al margen de una relación dialéctica y, hasta si se apura, dialógica con el que era el polo central de referencia cultural de aque-

\footnotetext{
${ }^{69}$ Véase expuesta de una manera descarnada esta perspectiva en un reciente libro dedicado a maestras y maestros republicanos represaliados y asesinados por el franquismo (María Antonia IGLESIAS, Maestros de la República (Los otros santos, los otros mártires), Madrid, La Esfera de Libros, 2006).

70 Jaume Claret Miranda, El atroz desmoche (La destrucción de la Universidad española por el franquismo. 1936-1945), Barcelona, Crítica, 2006, p. 8.

${ }^{71} \mathrm{Ibid}$.

Hispania Sacra, LIX

120, julio-diciembre 2007, 707-740, ISSN: 0018-215-X
} 
lla España: la Institución Libre de Enseñanza. Desde un análisis profundo de esta relación es posible comprender mejor la actividad y la configuración propias de la Institución Teresiana. Porque ésta no es, simplemente, el negativo de la ILE, pero sin lo que significó ésta no puede determinarse con claridad el anclaje de aquélla en la incipiente modernidad española, a la que también aportó el bagaje católico español así como el de las novedades católicas europeas. El programa de fe y ciencia que Poveda desarrolla explícita y constantemente desde 1919, aunque está implícito en el origen mismo de su reflexión, se alimentó, por tanto, de una realidad histórica concreta y trató de inculturarse en ella.

Este hecho lo sitúa, una vez más, en un terreno incómodo. El pensamiento nacional-católico hizo de la escuela republicana y de sus maestros el germen de todos los males y las violencias que justificaron el golpe de Estado denominado «Alzamiento Nacional». En los hombres de la ILE bien podía simbolizar a aquellos «sembradores de la semilla del odio» que, en alusión dantesca, estaban, a su juicio, en el origen de la persecución religiosa. De hecho, Poveda forma parte de un martirologio que, desgraciadamente, parece seguir siendo una herida enquistada en la psicología colectiva española. Asesinado por anarquistas de la CNT el 28 de julio 1936, la causa aducida, según recogen sus biógrafos, era que hacía mucho mal a la enseñanza laica. En este contexto, es lógico el silencio, sólo roto por alusiones, que las estudiosas de la Institución Teresiana han dejado caer sobre el impacto y la acogida de las novedades institucionistas por parte de su Fundador.

Para acabar y a modo ilustrativo de la conexión entre el espíritu de la Institución Teresiana, que, a juicio de su Fundador, había de modelarse a semejanza de la vida de los primeros cristianos, y la presencia en la enseñanza pública, que implicaba asumir y dialogar hasta el límite con las exigencias que su desarrollo planteaba, me atrevo a presentar una serie de citas povedanas a partir de 1928 que reafirman, en la memoria del protagonista, la coherencia de toda una trayectoria (de Guadix a Covadonga) basada en la fidelidad espiritual e histórica al carisma de la Institución proyectada en Covadonga y llevada a la práctica a lo largo de su vida. Adviértase además que entre 1931 y 1936 Poveda recapitula con frecuencia sobre los orígenes de su Obra, «de su modalidad específica, de su espíritu y programa, de su desarrollo» ${ }^{72}$.

En diciembre de 1928, exclama en una carta a un centro ${ }^{73}$ :

«Covadonga es para la Institución algo singular, único y para mí algo más singular y único. La santa Cueva será siempre la verdadera cuna de nuestra amadísima Obra. Ante la

\footnotetext{
72 Dolores Gómez MolledA, «Estudio introductorio», p. 964.

${ }^{73}$ Detrás de cada cita se incluirá el número de página según la edición del primer volumen de las Obras.
} 
imagen de la Santina se oró, se proyectó, se vio, por decirlo así, el desarrollo de la Obra» (p. 822).

El 29 de abril de 1934, en una exposición oral, al hacer recuento de las vicisitudes que precedieron a su llegada a Covadonga, señala: «Es una gloria para la Institución haber nacido en Covadonga; es sellarla con un sello de especialísima protección. Todo fue providencial en mi nombramiento para Covadonga [...] La Santísima Virgen quería que yo fuera allí para que allí naciera la Institución. No es sólo eso; los primeros pasos de mi pobre apostolado se hicieron con la Santísima Virgen [Guadix]» (p. 1143).

También en 1934 comienza a hablar ante las teresianas no sólo de cuándo sino de cómo nació su Institución. En una exposición oral del 12 de noviembre, transcrita por una de las asistentes, deja claro que ya en la época se reconocía no sólo el paralelismo con la ILE sino que gran parte de la animadversión de ésta procedía, precisamente, de que la Institución Teresiana no era una obra más de enseñanza privada sino que intervenía en el campo público, el cual los institucionistas querían que fuese, según ellos, neutro; según sus oponentes, suyo. Sin corroborarlo, no desmiente esta estrategia:

«En 1906 estando de canónigo en Covadonga pudimos conocer la actividad que la Institución Libre de Enseñanza estaba desarrollando en la Universidad de Oviedo y seguir con vivo interés su labor. Aprendí mucho de ellos en lo relativo a su modo de actuar en la enseñanza pública. Cuando el 30 de mayo de 1920, habló el Sr. Zulueta en el Congreso de los diputados de nuestra Institución, después de alabarla, diciendo que venía a llenar una necesidad con la creación de internados, criticó que preparase docentes para la enseñanza pública, a lo que algunos diputados le objetaron que, en eso, no hacíamos más que seguir el camino que ellos habían iniciado» (p.1169; la cursiva es mía).

Flavia Paz Velázquez recoge también el testimonio de otro manuscrito que recoge las charlas de aquel día. En él se explicita la conexión entre la presencia en la enseñanza pública y la espiritualidad de los primeros cristianos:

«La idea de que los miembros de la Institución Teresiana han de tomar como modelo de su vida la de los primeros cristianos, es un pensamiento que nació con la idea misma de la Obra; lo mismo que la característica de ocupar puestos en la enseñanza oficial. Son dos pensamientos capitales $[\ldots]\rangle^{74}$.

Por mi parte, es posible documentar también una tercera fuente de aquellas charlas, reproducida en uno de los volúmenes entregados en el Proceso de Beatificación, en que la conexión no deja ya lugar a dudas:

${ }^{74}$ Flavia Paz Velázquez, Las Academias (Cuadernos Biográficos Pedro Poveda 5), Madrid, Narcea, 1996, p. 123. Los puntos suspensivos son de la propia biógrafa de Poveda.

Hispania Sacra, LIX

120, julio-diciembre 2007, 707-740, ISSN: 0018-215-X 
«Los dos pensamientos principales de la Institución son pues: la cristianización de la enseñanza oficial, copiando en lo externo lo que hacía la ILE y en lo interno la imitación de la vida de los primeros cristianos. Que sepan siempre las que vengan a la Obra, de dónde nació esta idea» ${ }^{75}$.

A la luz de estas palabras, se comprenden mucho mejor el sentido del discurso de Poveda el 18 de julio de 1935, durante unos cursillos de orientación pedagógica celebrados en León entre julio y septiembre de 1935:

«Las profesoras «aisladas» son la forma sustancial de la Institución y vosotras, que habéis estudiado filosofía, sabéis que la forma sustancial es aquello por lo que una cosa es lo que es, y no otra [...] La Institución tiene semejanza con otras instituciones de enseñanza católicas; pero ¿hay algo que sea típico de la Institución? Sí, la preparación para la docencia en la enseñanza pública. Ésa es la característica principal de la Institución» (p. 1247) 76 .

Huelga decir que esta «característica principal» no aparecía ni por asomo en el apostolado de Guadix. Sin duda, el interés pedagógico nació en la población granadina, pero resulta difícil seguir manteniendo, de acuerdo con estas palabras, que la finalidad de la Institución Teresiana continúa siendo sólo la preocupación de regeneración social. Mejor dicho, podría decirse que ésta es la motivación común tanto en Guadix como en Covadonga, pero no puede concederse que sus objetivos y sus finalidades sean los mismos. De lo contrario, serían inexplicables los problemas de Poveda tanto con la ILE como con sectores católicos. Unas pocas líneas más abajo, él mismo retoma la argumentación de Luis de Zulueta, consignada hace poco, para remachar la actualidad «providencial» de su Obra:

«Se persigue no a tal o cual profesora, sino al hecho de que trabaje en la enseñanza pública [habla de la intervención de Zulueta y de la campaña escrita posterior contra la Institución]. Estar en la enseñanza pública y ser de la Institución no podía tolerarse, ¿qué importa que la escuela sea laica, si la maestra es católica? Esto es lo que argumentó R. Llopis. No critican los internados ni las academias, ¡ los tienen tantas religiosas...! Lo que interesa es que las personas de la Institución no desempeñen docencia en la enseñanza pública» (pp. 1247-1248).

75 A. Pego Puigbó, op. cit., p. 226. El volumen del Proceso se encuentra en el Archivo Histórico de la Institución Teresiana bajo el título de Doctrina Oral (1933-1934). Instrucciones. El documento en cuestión se titula «Instrucción a Teresianas de Madrid. Historia de la Obra. Madrid, 12 de noviembre de $1934 »$, p. 65.

${ }^{76}$ Con el término teresianas «aisladas» «se denominaba en lenguaje familiar a los miembros de la Institución que trabajaban como profesionales en la enseñanza pública, generalmente en lugares alejados de los centros propios de la Obra; en especial, las maestras de la enseñanza primaria, que vivían en núcleos rurales y dispersos por toda la geografía nacional» («Aparato crítico y notas complementarias (1935)» en Pedro PovedA, Obras, p. 1287). 
Para los institucionistas era intolerable, a juicio de Poveda. ¿Podía serlo para la doctrina oficial del catolicismo español? En 1902 Manjón había dejado claro que la escuela debía ser cristiana, de modo que «si, pues, viniera un organizador de la acción social docente, vulgo escuela, a sustraer ésta a la autoridad y vigilancia de los padres y la Iglesia, dejaría aquella de ser cristiana en derecho, aunque de hecho la rigieran buenos maestros» ${ }^{77}$. Aunque desde la primera edición del Ensayo de proyectos pedagógicos denunció explícitamente la acción de la ILE, rebajando el mérito pedagógico de sus iniciativas, lo que hacía era abogar por reapropiárselas para llenarlas de contenido católico, en lugar de considerar sus estrategias -que no sus fines-incompatibles con el modelo cristiano ${ }^{78}$. En este sentido, no deberían sorprender, por tanto, las reticencias que suscitaba la propuesta povedana. No se trata, entonces, de que llegase pronto a la cita con su momento histórico sino de una causa mucho más profunda: sin apartarse un ápice de la doctrina católica sobre la educación, tal como había sido sancionada por León XIII y después por Pío XI, planteaba un análisis de la realidad rechazada por la jerarquía y proponía unas respuestas que, en función de ese rechazo, no se podían compartir. Se reconocía su celo, se le elogiaba por ello, pero no se le hizo caso.

Podría argumentarse que la tensión del momento habría llevado en 1935 a realzar una de las facetas de la labor social contenida en su ideario pedagógico. Una vez más, hay que recordar que en 1911 había sido claro sobre los objetivos de su Institución Católica de Enseñanza. Y en el texto que comentamos se refuerza la idea original:

«La Institución se fundó para formar maestras cristianas que trabajaran en la enseñanza pública, y lo demás son sólo medios para llegar a este fin. Lo dice precisamente el último Breve» (p. 1248; la cursiva es mía).

Unas dos semanas más tarde, el 5 de agosto, en un curso de orientación para docentes, volvía sobre los orígenes de su programa y no cejaba en la repetición:

«Todas las cosas que yo entonces pensaba o hacía se referían a esto: los católicos gastan dinero, tiempo, etc., en la enseñanza privada, si el esfuerzo se dirigiera a la enseñanza oficial, habríamos dado un paso importante a favor de la educación. Conocía la labor de la Institución Libre, que empezó dejando la enseñanza oficial, enfrentándose con el Estado y acabó por ocupar los puestos oficiales, protegidos y amparados por el mismo Estado [...]. Los gobiernos procurarán extender sus centros de enseñanza y el profesorado estatal a todos los

\footnotetext{
${ }^{77}$ Andrés MANJón, Los padres de familia y el problema de la enseñanza (Discurso leído en el Congreso Católico de Compostela), Madrid, Tipografía del Sagrado Corazón, 1902, p. 36.

${ }_{78}^{78}$ Pedro Poveda, Folletos, edición facsímile e a cargo de Encarnación González, Madrid, Publicaciones del Archivo de la Institución Teresiana, 1989, pp. 37-38, 79-80.
}

Hispania Sacra, LIX

120, julio-diciembre 2007, 707-740, ISSN: 0018-215-X 
pueblos; es urgente la formación de maestros católicos. Todo esto lo decía yo en Proyectos pedagógicos, que parece escrito después de los sucesos acaecidos el año 1931; había en esa publicación una visión anticipada de todo lo que iba a ocurrir» (p. 1262).

Las Academias no son, en consecuencia, sólo la manera de colaborar en la renovación pedagógica, con un estilo colaborador y singular. Para Poveda, eran un medio, no un fin en sí mismas; el único medio del que disponía para poner en práctica su programa, que contemplaba la posibilidad de su creación: «Empecé haciendo lo que podía hacer entonces, abrir unas academias donde se preparase a la juventud femenina para el ingreso en la Normal y para opositar después a los puestos de la enseñanza oficial» (p. 1263).

Con fisonomía propia, espiritual y pedagógica, elaboró un modelo de creyentes con el que las Academias buscaban no sólo instruir sino sobre todo formar a sus alumnas con el fin de que ese espíritu acabase penetrando en la escuela pública con su testimonio profesional y personal. El 5 den abril de 1936, al recordar la fundación de la Residencia de Madrid en 1914, insistía en que «la razón de ser de nuestros internados, que para nosotros no son un fin, sino medios de que la Institución se vale para formar a las estudiantes y prepararlas para la docencia en los centros de enseñanza pública» (pp. 1305-1306).

Las maestras teresianas debían compartir, pues, la misma ansia de regeneración social de las maestras y los maestros laicos, desde una oposición ideológica tanto más dramática y explosiva cuanto irreductible por el hecho de pertenecer al mismo cuerpo docente. El hecho de no ser miembros de comunidades religiosas ni de formar parte de la enseñanza privada, las insertaba en la vanguardia del proceso secularizador. De ahí continúan surgiendo las paradojas y los interrogantes que suscita la poliédrica personalidad de Pedro Poveda.

\section{CONCLUSIÓN}

Tras este recorrido, es razonable lamentar que la fama del sacerdote linarense no se haya extendido tanto como merecería ${ }^{79}$. Es cierto que existen importantes lagunas en el conocimiento de su figura, pese a su indudable importancia. Queda aún por conocer con detalle el último periodo de su vida, muy rico en el desarrollo de su espiritualidad y en la multiplicación de las iniciativas llevadas a cabo por la Institución Teresiana, entre la Dictadura de Primo de Rivera y la II República.

79 Véanse fechas, revistas y editoriales de la bibliografía ofrecida en el volumen dedicado a su canonización (Encarnación González Rodríguez (coord.), San Pedro Poveda Castroverde. Canonización (4 de mayo de 2003), Madrid, Fundación Institución Teresiana, 2005, pp. 515-522). 
Más conflictivo y delicado resulta el análisis de su pensamiento político. A pesar de los vínculos republicanos de su familia paterna, que debieron de influir en una actitud vital tolerante, acentuada por la convivencia con la adscripción conservadora de la rama materna, en algunos escritos povedanos de Covadonga se advierten ecos del tradicionalismo español, que identifica patria con religión. Posteriormente se concentra en ahondar en una espiritualidad propia que, apoyándose en las tradiciones piadosas de su época, intenta trascenderlas para alcanzar el nervio de la actitud cristiana en medio de una sociedad secularizada ${ }^{80}$. En todo caso, faltan estudios que permitan filiar la posición de Pedro Poveda en la trayectoria del catolicismo social español entre el siglo XIX y el siglo XX. No se trataría de aventurar cuál opción política prefería, sobre lo que siempre se mantuvo cauto, sino de establecer las bases ideológicas, y no sólo espirituales, de su compromiso social y pedagógico.

En el terreno de la difusión de sus obras queda mucho por hacer. Desde la benemérita edición de Ángeles Galino, publicada hace más de cuarenta años, y de la antología Amigos fuertes de Dios de Dolores Gómez Molleda, apenas hay disponibles ediciones de obras de Poveda dirigidas a un público amplio, no estrictamente vinculado a la Institución Teresiana. Por fortuna, han surgido iniciativas últimamente a favor de un conocimiento más amplio de su obra, como la edición de la obra Jesús, Maestro de oración, con una introducción extensa y detallada a cargo de Encarnación González, o la elaboración de los volúmenes de sus Obras. Es de destacar también la labor de la Cátedra Pedro Poveda de la Universidad Pontificia de Salamanca que, amén de organizar cursos universitarios de libre configuración en torno a la los problemas del diálogo fe-ciencia, ha iniciado la publicación de una colección que incluye estudios sobre la figura de su titular ${ }^{81}$.

A estas alturas estará de más recordar que el objetivo de las páginas precedentes no ha sido la «modalidad específica» o el «espíritu» de la Institución Teresiana sino resaltar uno de los cauces, no por más evidente más tratado, que confluyeron y ayudaron a delinear críticamente las líneas del programa povedano y su posterior desarrollo. Este programa, injustamente preterido, requiere ser recuperado para un mejor conocimiento de la originalidad y la riqueza de un conflictivo periodo histórico. En este sentido, Pedro Poveda no pertenece ni a la historia «religiosa» ni a la historia «civil» sino que, por derecho propio, es protagonista de un capítulo, con sus luces y sus sombras, de la historia contemporánea española a secas.

\footnotetext{
${ }^{80}$ Felipe Fernández Ramos, Espiritualidad bíblica en las «Consideraciones» de Pedro Poveda, Madrid, Narcea, 1989.

${ }^{81}$ Pedro PovedA, Jesús, Maestro de oración, estudio preliminar y edición crítica de M ${ }^{\mathrm{a}}$ Encarnación González, Madrid, BAC, 1997 (segunda edición corregida y actualizada, 2001); G. BoMBARDIERI y C. Morano (eds.), Pedro Poveda: nuevos caminos en la Iglesia, Salamanca, Universidad Pontificia (col. Cátedra Pedro Poveda 2), 2004.
}

Hispania Sacra, LIX

120, julio-diciembre 2007, 707-740, ISSN: 0018-215-X 